\title{
A COMPETITIVIDADE DA AGROINDÚSTRIA DE LATICÍNIOS: UMA INVESTIGAÇÃO NO ESTADO DO PARÁ
}

\author{
Carlos André Corrêa de Mattos* \\ Glenda Maria Braga Abud** \\ Nilson Luiz Costa**** \\ Antonio Cordeiro de Santana***
}

RESUMO: O objetivo deste artigo é analisar as estratégias competitivas, utilizadas pelas empresas de laticínios do Estado do Pará. A pesquisa, classificada como exploratória e descritiva, foi realizada na forma de censo e teve como universo as empresas fiscalizadas pelo Serviço de Inspeção Federal (SIF/MAPA) e Estadual (SIE/ ADEPARÁ). Ao final da pesquisa, foram realizadas 30 entrevistas, com empresas que aceitaram responder ao questionário. A interpretação dos resultados utilizou indicadores, construídos por técnicas matemáticas e estatísticas, entre eles, o Índice de Desempenho Competitivo (IDC), que possibilitou ranquear as empresas e indicou que apenas $6,7 \%$ delas apresentavam alta competitividade, e a análise fatorial, que explicou $80,46 \%$ da variância em quatro fatores denominados como Estrutura de Produção (37,97\%), Gestão Empresarial (15,89\%), Ambiente Locacional $(14,89 \%)$ e Desempenho Competitivo (11,89\%). As conclusões revelaram que as empresas ganharam competitividade nos últimos anos, tendo por base a busca por maiores volumes de produção, economia de escala e participações de mercado, estratégias alinhadas ao mercado de commodities e aos modelos de competitividade estruturalistas. Contudo a manutenção desse processo demanda ações conjuntas da cadeia de produção e da implementação de políticas públicas, destinadas, principalmente, às empresas de menor porte e de fiscalização estadual.

PALAVRAS-CHAVE: Cadeia de produção; Leite e derivados; Análise fatorial; Índice de desempenho competitivo.

Doutor em Ciências Agrárias. Docente permanente do Programa de Mestrado Profissional em Gestão Pública do Núcleo de Altos Estudos Amazônicos (NAEA) e da Faculdade de Administração (FAAD) da Universidade Federal do Pará (UFPa), Brasil. E-mail: carlosmattos@ufpa.br

** Técnica em Planejamento da Empresa de Assistência Técnica e Extensão Rural do Estado do Pará (EMATER/ $\mathrm{Pa})$, Brasil.

*** Doutorado em Ciências Agrárias pela Universidade Federal Rural da Amazônia. Docente do curso de Ciências Econômicas do Campus de Palmeira das Missões da Universidade Federal de Santa Maria e líder do Grupo de Pesquisas em Economia, Agricultura Familiar e Agronegócios (GPEA-UFSM), Brasil.

**** Doutorado em Economia Aplicada pela Universidade Federal de Viçosa. Docente Titular da Universidade Federal Rural da Amazônia. Pró-reitor de Planejamento e Desenvolvimento Institucional da UFRA. Brasil. 


\section{COMPETITIVENESS OF DAIRY AGROINDUSTRY IN THE STATE OF PARÁ, BRAZIL}

ABSTRACT: Competition strategies used by dairies in the state of Pará, Brazil, are provided. Current exploratory and descriptive census-like research focused on companies monitored by the Federal and State Inspection Service (SIF/MAPA and SIE/ADEPARÁ). Thirty interviews were applied at the end of the research with complying companies. Results were interpreted by employing indexes, built by mathematical and statistical techniques, especially the ranking Competitive Performance Index (CPI). CPI showed that only $6.7 \%$ of the companies had high competitiveness, coupled to factorial analysis with $80.46 \%$ of variance in four factors, namely, Production Structure (37.97\%), Entrepreneur Management (15.89\%), Site Environment (14.89\%) and Competitive Performance (11.89\%). It may be concluded that companies achieved competitiveness during the last decades, based on greater production, scale economy, market participation, strategies aligned to the commodity market and to structural competitive models. However, the maintenance of the process demands corporative activities within the production chain and the implementation of public policies mainly for small-size state-monitored firms.

KEY WORDS: Production chain; Milk and derivatives; Factorial analysis; Competitive performance index.

\section{INTRODUÇÃO}

Nas últimas décadas, o mercado de lácteos no Brasil observou um intenso processo de fusões e aquisições, especialmente no segmento industrial, com o propósito de ampliar a capacidade de processamento dos laticínios (CARVALHO, 2011). Essa estratégia foi justificada pela necessidade de ganhos de escala e eficiência, para reduzir custos logísticos e fazer frente ao grande poder de barganha das redes varejistas, principalmente a de supermercados, onde se concentra o maior gasto com alimentação das famílias (BARROS et al., 2001; TAYRA; SILVEIRA, 2011).

A adoção dessas estratégias pelas empresas de laticínios alterou o ambiente da cadeia de produção e colocou em perspectiva sua capacidade de atuar em mercados mais competitivos. No Estado do Pará, 41 empresas têm licença ativa no Ministério da Agricultura, Pecuária e Abastecimento - Divisão de Produtos de 
Origem Animal (MAPA/DIPOA) - e na Agência de Defesa Agropecuária do estado do Pará (ADEPARÁ). Essas empresas atuam distribuídas em 29 municípios e contam com capacidade de processar 625.500 L por dia, conforme as quantidades médias registradas nas agências de fiscalização.

No Estado do Pará a primeira empresa a atender às exigências da legislação sanitária federal, ainda em operação, foi inaugurada em 1987 e, no âmbito da fiscalização estadual, em 1995. A implantação das empresas de laticínios no Estado se intensificou a partir do ano 2000, quando ocorreu o maior número de inaugurações. Contudo, apesar de três décadas de atuação, o segmento carece de estudos de competitividade, e nessa perspectiva esta pesquisa busca contribuir para reduzir essa lacuna.

A análise da competitividade das empresas de laticínios assume relevância especial quando são consideradas as características do Estado do Pará no que concerne às características do rebanho, à presença de áreas de pastagens e à necessidade de se promover sua utilização mais racional e sustentável. Competitividade é um conceito complexo, que pode ser compreendido em diferentes perspectivas (empresa, setor ou nação) e, portanto, avaliado por um amplo conjunto de indicadores.

A competitividade empresarial diz respeito à habilidade em se lidar com a concorrência e resulta da capacidade de se absorver conhecimento e transformá-lo em valor (CASTRO; HURTADO; BARRÁEZ, 2013; THOMÉ; FERREIRA, 2014; COSTA et al. 2015). Dessa forma, a competitividade constitui-se em processos dinâmicos, com base na aprendizagem e no aprimoramento, que, estruturado a partir da utilização de recursos e desenvolvimento de competências, qualifica a empresa para atuação no mercado e poderá resultar em desempenho superior, quando o valor acrescido superar os demais integrantes do mesmo ambiente competitivo (HORTA; SILVEIRA; CAMACHO, 2015). Em síntese, a competitividade constitui-se na adequação dos produtos e aprimoramento de processos organizacionais (ROMAN et al. 2012).

Nesse contexto, o problema de pesquisa a que este estudo se propõe responder é: Quais as características das empresas de laticínios no Estado do Pará e como essas empresas atuam competitivamente? Para tanto, o objetivo estabelecido para a investigação foi analisar as estratégias competitivas, utilizadas pelas empresas de laticínios do Estado do Pará, que são inspecionadas pelo Serviço de Inspeção 
Federal (SIF) do Ministério da Agricultura, Pecuária e Abastecimento (MAPA) e Inspeção Estadual (SIE) da Agência de Defesa Agropecuária do Estado do Pará (ADEPARÁ) para atuarem no mercado.

A atividade leiteira é naturalmente complexa, e pesquisas com essa temática podem fundamentar estratégias empresariais e políticas públicas para o setor de forma a contribuir para o fortalecimento da atividade, atraindo investimentos, identificando a necessidade de infraestrutura, de capacitação de produtores ou mesmo de desenvolvimento e implantação de tecnologias adequadas à realidade regional e, assim, atuar para o desenvolvimento do Estado.

\section{MATERIAL E MÉTODOS}

A pesquisa é classificada como um estudo exploratório e descritivo, com abordagem quantitativa, operacionalizada em pesquisa de campo. A coleta de dados ocorreu na forma de censo e caracterizou um estudo ex-post-facto (MARTINS, 2010). No universo de 41 empresas de laticínios, registradas no Estado, 30 participaram da coleta de dados, uma vez que quatro estavam desativadas e sete se recusaram em responder ao questionário. $\mathrm{O}$ instrumento de coleta de dados foi adaptado às particularidades e à realidade regional, a partir do questionário desenvolvido pela REDESIST (Rede de Pesquisas em Sistemas e Arranjos Produtivos e Inovativos Locais).

$\mathrm{O}$ tratamento dos dados foi quantitativo, com técnicas de estatística descritiva e multivariada.

A compreensão da competitividade foi realizada pelas variáveis na forma como foram respondidas no questionário e pela elaboração de indicadores, utilizados para representar o desempenho ou a importância atribuída aos aspectos da competitividade, expressos na forma de índices, que assumiram valores entre 0 (zero) e 1 (um). Assim, quanto mais próximo de 1 (um), mais intenso ou importante foi considerado o indicador, da mesma forma que, ao aproximar-se de 0 (zero), revela-se indiferença ou ausência.

$\mathrm{Na}$ interpretação dos indicadores, valores abaixo de 0,4000 foram considerados baixos; entre 0,4001 e 0,6999, intermediários; e valores acima 0,7000, 
altos. A necessidade da construção de indicadores está em sua capacidade de transformar atributos qualitativos, representados pela intensidade de importância ou concordância, em quantitativos, possibilitando seu tratamento com técnicas estatísticas e matemáticas. Após a construção dos indicadores, eles foram utilizados nas análises descritivas e multivariadas, como realizado por Stallivieri, Campos e Britto (2009), Britto et al. (2007), entre outros. Os indicadores utilizados foram:

Acesso ao mercado interestadual (X1): variável Dummy se relaciona ao cadastro no serviço de fiscalização federal (SIF). Assumiu valor 1 (SIF) e 0 (SIE); faturamento mensal (X2): expresso em reais (R\$), corresponde à receita operacional bruta, calculada pela média mensal anual. Representa as atividades produtivas e indica o tamanho da empresa quanto ao faturamento; capacidade de produção diária (X3): indica o limite máximo da capacidade produtiva em litros por dia. Representa a medida das possibilidades de produção. Mede a taxa de ocupação de máquinas e equipamentos; quantidade produzida diária (X4): mede a captação de leite. Relaciona-se tanto com o nível de produção diário, quanto com a oferta de leite na região. Variável expressa em litros por dia, sendo limitada pela capacidade instalada, potencial de vendas, recursos humanos, financeiros e gerenciais das empresas; gasto com a aquisição de matéria prima (X5): expressa o custo de aquisição do leite, principal custo da indústria. Mede o desembolso em reais $(\mathrm{R} \$)$, resultado da quantidade produzida diariamente, multiplicada pelo preço do leite pago ao produtor rural na plataforma da indústria; importância atribuída aos insumos (X6): representa o índice entre 0,000 e 1,000, que mede a importância atribuída aos insumos. Envolve matéria prima utilizada, equipamentos, técnicas de negociação, preços de vendas e condições de pagamento, entre outras; evolução do desempenho competitivo (X7): índice entre 0,000 e 1,000, que expressa a evolução do desempenho nos últimos cinco anos, resume a evolução das vendas, participação de mercado, número de empregos e lucratividade, possibilita compreender o quanto as empresas têm melhorado sua posição competitiva; inovações em processos (X8): índice entre 0,000 e 1,000, que representa a quantidade de inovações realizadas para melhorar a produtividade e a eficiência produtiva, avalia a aquisição de máquinas e equipamentos que melhoraram o processo produtivo e a qualidade dos produtos oferecidos pelas empresas; vantagem locacional (X9): índice entre 0,000 e 1,000, 
que sintetiza as vantagens fundamentadas na localização. Reúne oferta de matéria prima de qualidade, custo e qualidade da mão de obra, acesso à assistência técnica, presença de programas de apoio à produção, entre outros; contribuição de sindicatos e associações (X10): índice entre 0,000 e 1,000, que mede a atuação das entidades de classe na representação do setor, avalia as entidades em sua atuação junto ao governo e na liderança do setor; contribuição de políticas públicas (X11): índice entre 0,000 e 1,000, que avalia a importância das políticas públicas para a competitividade. Examina aspectos relacionados à eficiência competitiva quanto à infraestrutura local, oferta de financiamentos e linhas de crédito, programas de apoio à produção, entre outros; tamanho da empresa (X12): classifica o tamanho das empresas quanto ao número de funcionários (SEBRAE, 2015), possibilita avaliar as relações estabelecidas entre a competitividade das empresas e o número de postos de trabalho, assume valores entre 1 (um) e 4 (quatro) de ordem crescente quanto à quantidade de postos de trabalho; e limitações de acesso ao crédito (X13): índice entre 0,000 e 1,000, que possibilita compreender a intensidade das restrições no acesso ao crédito. Compreendem aspectos gerais da política de financiamento industrial, especialmente quanto a taxas de juros, burocracia, garantias e demais aspectos relativos aos financiamentos.

A consistência interna foi auferida pelo coeficiente alpha de Cronbach $(\alpha)$, e sua utilização possibilitou verificar se havia um padrão de resposta. A partir da matriz, foi aplicada a análise fatorial para se identificar aspectos dificilmente observáveis com a utilização de outras técnicas. O modelo de análise fatorial (1) pode ser representado na forma matricial, conforme Dillon e Goldstein (1992):

$$
\mathrm{X}=\alpha \mathrm{F}+\varepsilon
$$

Em que $X$ é o p-dimensional, vetor transposto das variáveis observáveis, denotado por $\mathrm{X}=\left(\mathrm{x}_{1}, \mathrm{x}_{2} \ldots, \mathrm{x}_{\mathrm{p}}\right)^{\mathrm{t}} ; F$ é o q-dimensional, vetor transposto das variáveis não observáveis ou variáveis latentes, denominadas de "fatores comuns", denotados por $\mathrm{F}=\left(\mathrm{f}_{1}, \mathrm{f}_{2}, \ldots, \mathrm{f}_{\mathrm{q}}\right)^{\mathrm{t}}$, sendo $\mathrm{q}<\mathrm{p} ; \varepsilon$ é o p-dimensional, vetor transposto de variáveis aleatórias ou fatores únicos, $\varepsilon=\left(\mathrm{e}_{1}, \mathrm{e}_{2}, \ldots, \mathrm{e}_{\mathrm{p}}\right)^{\mathrm{t}}$; e $\alpha$ é a matriz $(\mathrm{p}, \mathrm{q})$ de constantes desconhecidas, denominadas de "cargas fatoriais". 
O ranking de competitividade foi estabelecido pelo Índice de Desempenho Competitivo (IDC). Essa metodologia possibilita a ordenação de elementos pelos resultados da análise fatorial (SANTANA, 2007). O índice é calculado pela ponderação das cargas fatoriais, e a forma de cálculo possibilita reunir os escores fatoriais, sintetizando-os em um único índice e, assim, compreender a competitividade por um fator comum. Essa metodologia estabelece um ordenamento que possibilita a classificação da competitividade em forma de ranking. O cálculo é feito com base na matriz de escores fatoriais, em que, para cada fator $\boldsymbol{f}_{j}$, o i-ésimo escore fatorial extraído é definido por $F_{i j}$, expresso por meio de uma combinação linear (2), conforme Soares et al., 1999; Gama et al., 2007; Santana et al., 2009; Santos et al., 2014, entre outros.

$$
F_{i j}=b_{1} x_{i 1}+b_{2} x_{i 2}+\ldots+b_{p} x_{\dot{p}} ; i=1,2, \ldots, n ; j=1,2, \ldots, p
$$

Em que $b_{i}$ são os coeficientes de regressão estimados para os $n$ escores fatoriais comuns; $x_{i j}$ são as $n$ observações das $p$ variáveis observáveis, padronizadas pelo método Z-score para apresentar uma distribuição com média 0 e desvio igual a 1. A variável $F_{i j}$ não é observável, mas pode ser estimada, utilizando-se a análise fatorial, por meio da matriz de observações do vetor $x$ de variáveis observáveis. Assim, o IDC (3) resulta de uma combinação linear dos escores fatoriais e da proporção da variância explicada por cada fator em relação ao total da variância, explicada pelos fatores comuns:

$$
I D C_{i}=\sum_{j=1}^{q}\left(\frac{\lambda_{j}}{\sum_{j} \lambda_{j}} P_{j}\right)
$$

Em que $\lambda_{j}$ é a variância explicada por cada fator; e $\sum \lambda_{j}$ é a soma total da variância explicada pelo conjunto de fatores comuns. Os escores fatoriais utilizados para o cálculo do IDC foram previamente padronizados (FP) para se obter valores positivos dos escores originais (4) e permitir que as empresas fossem hierarquizadas. 
Esse procedimento possibilitou construir um ranking de competitividade, pois os valores do IDC estão situados no intervalo entre 0,000 (zero) e 1,000 (um).

$$
P_{i}=\left(\frac{F_{i}-F_{\text {min }}}{F_{\text {máx }}-F_{\text {min }}}\right)
$$

Em que Fmin e Fmax são os valores mínimos e máximos dos escores fatoriais associados às variáveis, respectivamente.

\section{Resultados e discussão}

Os entrevistados atuavam em cargo de gerência e direção em 100\% (30) dos casos e mostraram conhecer o setor, uma vez que $83 \%$ (25) deles tinham mais de cinco anos de experiência. Entre os principais objetivos das empresas de laticínios, posicionaram-se, em ordem decrescente de prioridade, o aumento do tamanho da empresa, a implantação do transporte a granel e o resfriamento do leite nas propriedades rurais.

Quanto à localização, as empresas que participaram da pesquisa estavam distribuídas em 24 municípios do Estado do Pará, predominantemente no sudeste do Estado, sendo 83\% (25) das entrevistas realizadas nas regiões dos rios Capim, Carajás e Araguaia. A distribuição amostral, quanto às agências de fiscalização, foi formada por $60 \%$ (18) de empresas com inspeção federal e $40 \%$ (12) estadual. Quanto à utilização da capacidade instalada, a maior parte as empresas (33\%) operava com até $10 \%$ de ociosidade na safra (outubro a março) e acima de $50 \%$ na entressafra (40\%).

O queijo mozarela é produzido por 90\% (27) das empresas e representa em média 79,12\% da produção total, sendo o principal produto do setor no Estado. As empresas geram 968 postos de trabalho, e a escolaridade dos recursos humanos é baixa: 61,8\% (599) têm até o nível fundamental completo. Existem programas de quantificação de mão de obra, concentrando-se principalmente em boas práticas de fabricação e, junto aos produtores rurais, especificamente em higiene na ordenha, com 16,66\% (5) e 10,00\% (3) das respostas, respectivamente. Apenas $20 \%$ (6) das 
empresas afirmaram desenvolver ações ou possuir algum tipo de certificação de responsabilidade socioambiental, além das exigidas pela legislação.

A análise descritiva (Tabela 1) revelou predominância de empresas fiscalizadas pela inspeção federal (X1). A maior receita bruta média mensal (X2) foi de $R \$ 2.955 .600,00$ e a menor, $R \$ 28.700,00$. Capacidade de produção diária (X3), quantidade produzida diária (X4) e contribuição de sindicados e associações (X10) apresentaram diferenças maiores entre mediana e moda, indicando maior dispersão entre as respostas dos entrevistados.

Tabela 1. Estatística descritiva das variáveis utilizadas na pesquisa

\begin{tabular}{cccccccc}
\hline Variável & $\mathrm{N}$ & Amplitude & Mínimo & Máximo & Média & Mediana & Moda \\
\hline X1 & 30,00 & 1,00 & 0,00 & 1,00 & - & 1,00 & 1,00 \\
X2 & 30,00 & $2.926 .900,00$ & $28.700,00$ & $2.955 .600,00$ & $762.066,02$ & $672.616,04$ & $762.066,02$ \\
X3 & 30,00 & $238.500,00$ & $1.500,00$ & $240.000,00$ & $50.100,00$ & $25.000,00$ & $20.000,00$ \\
X4 & 30,00 & $129.700,00$ & 300,00 & $130.000,00$ & $27.636,67$ & $17.000,00$ & $32.000,00$ \\
X5 & 30,00 & $80.240,00$ & 360,00 & $80.600,00$ & $16.797,67$ & $11.050,00$ & $11.050,00$ \\
X6 & 30,00 & 0,7231 & 0,2769 & 1,0000 & 0,8051 & 0,8000 & 0,9385 \\
X7 & 30,00 & 0,7000 & 0,3000 & 1,0000 & 0,7733 & 0,8000 & 0,8000 \\
X8 & 30,00 & 0,7500 & 0,2500 & 1,0000 & 0,6833 & 0,7500 & 0,7500 \\
X9 & 30,00 & 0,8583 & 0,0750 & 0,9333 & 0,4456 & 0,4125 & 0,4917 \\
X10 & 30,00 & 1,0000 & 0,0000 & 1,0000 & 0,3361 & 0,2773 & 0,0000 \\
X11 & 30,00 & 0,3889 & 0,6111 & 1,0000 & 0,8930 & 0,9333 & 1,0000 \\
X12 & 30,00 & 2,00 & 1,00 & 3,00 & 1,77 & 2,00 & 2,00 \\
X13 & 30,00 & 0,7000 & 0,1333 & 0,8333 & 0,4833 & 0,4583 & 0,4583 \\
\hline
\end{tabular}

Fonte: Pesquisa de campo.

Observa-se que os entrevistados atribuíram elevada importância aos (X6) insumos para a competitividade $(0,8051)$, apresentaram alta $(X 7)$ evolução do desempenho competitivo $(0,7733)$ e avaliaram como importante a (X11) contribuição de políticas públicas para a competitividade $(0,8930)$. Assim, possibilitaram constatar que as matérias primas, o processo de fabricação e as práticas de gestão são elementos 
considerados relevantes pelos entrevistados, pois contribuem para melhorar a qualidade dos produtos (X6) e, por conseguinte, melhoram a competitividade. Nos últimos cinco anos, as empresas avançaram, tornando-se mais competitivas (X7).

Classificadas como intermediárias (0,4000 e 0,6999), observa-se a presença das variáveis (X8) inovações realizadas em processos $(0,6833)$, (X9) vantagens locacionais $(0,4456)$ e $(\mathrm{X} 13)$ limitações de acesso ao crédito $(0,4833)$. Destacaramse as variáveis relacionadas às (X9) vantagens locacionais e o (X13) acesso ao crédito, que se aproximam dos limites do estrato $(0,4000)$, indicando que poderiam contribuir mais para a competitividade. Completou a avaliação a contribuição dos sindicados e associações (X10) que, no geral, representou uma limitação na região, com média de 0,3361, e a atuação dessas entidades mostrou-se aquém do esperado. Finalmente a classificação do tamanho das empresas segundo o número de empregados (X12) mostrou a predominância de pequenas empresas com 20 a 99 funcionários (SEBRAE, 2015).

A aplicação da análise fatorial se iniciou pela verificação da adequação da amostra à técnica. $\mathrm{O}$ exame da matriz de correlações confirmou preliminarmente a adequação da amostra, mesmo se considerando seu reduzido tamanho, pois havia quantidade suficiente de correlações elevadas (médias e fortes), sendo 53,85\% delas significativas a 5\%. Esse diagnóstico foi confirmado pela determinante da matriz, com valor diferente de $0(2,13 \mathrm{E}-07)$. Os testes Kaiser Meyer Olkin $(0,726)$ e de esfericidade de Bartlett (366,111, significativo a 1\%) também confirmaram a adequação amostral. Concluídos os testes, foi aplicada a análise de componentes principais com rotação ortogonal pelo método Varimax.

A rotação fatorial reuniu as 13 variáveis em quatro fatores (Tabela 2) que explicaram $80,46 \%$ da variância total dos dados. A comunalidade $\left(\mathrm{h}^{2}\right)$ foi satisfatória, uma vez que todas as variáveis apresentaram valores superiores a 0,600. A consistência interna dos fatores foi testada pelo coeficiente alpha de Cronbach, com valores adequados para pesquisas exploratórias $(\alpha=0,775)$, segundo Hair et al. (2009). A exceção ocorreu no Fator 4, que obteve alpha de $\alpha=0,567$, pouco abaixo do recomendável. Para o cálculo do coeficiente, as variáveis foram previamente padronizadas pelo método $Z$-Score $\left(\mu=0\right.$ e $\left.\sigma^{2}=1\right)$, procedimento necessário para se evitar que as diferentes escalas comprometessem os resultados do alpha de 
Cronbach. Outro procedimento foi a inversão da escala negativa da variável X11, multiplicando-a por -1, uma vez que o cálculo do coeficiente não admite valores negativos.

Tabela 2. Matriz de componentes rotacionados e alphas de Cronbach

\begin{tabular}{llccccc}
\hline \multirow{2}{*}{ Variáveis } & \multicolumn{5}{c}{ Fatores } & \multicolumn{2}{c}{ h$^{2}$} \\
\cline { 3 - 6 } & \multicolumn{1}{c}{1} & 2 & 3 & 4 & \\
\hline X3 & Capacidade de produção diária & 0,962 & 0,121 & 0,023 & $-0,128$ & 0,744 \\
X4 & Quantidade produzida diariamente & 0,943 & 0,180 & 0,006 & $-0,082$ & 0,836 \\
X5 & Gasto com aquisição de matéria prima (leite) & 0,941 & 0,180 & $-0,013$ & $-0,093$ & 0,957 \\
X2 & Faturamento mensal & 0,857 & 0,109 & 0,050 & 0,294 & 0,929 \\
X12 & Tamanho da empresa & 0,850 & 0,170 & 0,028 & $-0,115$ & 0,926 \\
X13 & Acesso ao crédito & 0,040 & 0,895 & 0,082 & $-0,041$ & 0,871 \\
X8 & Inovações realizadas em processos & 0,480 & 0,634 & $-0,043$ & $-0,207$ & 0,888 \\
X1 & Acesso ao mercado interestadual (dummy) & 0,486 & 0,605 & $-0,368$ & 0,077 & 0,677 \\
X9 & Vantagem locacional & $-0,073$ & $-0,235$ & 0,829 & $-0,169$ & 0,775 \\
X10 & Contribuição de sindicados e associações & $-0,009$ & 0,081 & 0,779 & $-0,024$ & 0,614 \\
X6 & Importância atribuída aos insumos & 0,425 & 0,430 & 0,653 & 0,281 & 0,667 \\
X7 & Evolução do desempenho competitivo & 0,029 & 0,033 & 0,012 & 0,941 & 0,766 \\
X11 & Contribuição das políticas públicas & 0,317 & 0,360 & 0,257 & $-0,609$ & 0,810 \\
\hline Autovalores & 4,913 & 2,066 & 1,934 & 1,547 & 10,46 \\
Variância explicada & 37,97 & 15,89 & 14,89 & 11,89 & 80,46 \\
Coeficiente alpha de Cronbach & 0,959 & 0,741 & 0,671 & 0,567 & 0,775 \\
\hline
\end{tabular}

Fonte: Pesquisa de campo.

$\mathrm{Na}$ denominação dos fatores, o Fator 1 foi identificado como "Estrutura de Produção", pois reuniu variáveis relacionadas às quantidades produzidas e às receitas auferidas. O Fator 2 foi denominado "Gestão Empresarial" e captou aspectos do processo de gestão, especialmente inovações e mercados de atuação. O Fator 3 foi denominado "Ambiente Locacional", pois apresentou vantagens 
proporcionadas pela localização, principalmente quanto a aspectos produtivos. Finalmente, o Fator 4 foi denominado "Desempenho Competitivo", uma vez que reuniu aspectos da performance organizacional, associados a políticas públicas. A variável X11, contribuição das políticas públicas para a competitividade, apresentou carga fatorial negativa, indicando que as políticas existentes ou sua ausência não favorecem a competitividade das empresas no Estado.

O fator "Estrutura Produtiva" explicou 37,97\% da variância com elevada consistência interna $(\alpha=0,959)$. Este fator destacou aspectos das quantidades produzidas e seus reflexos na competitividade. A quantidade produzida é um fator clássico de competitividade, por contribuir para aumentar o poder de barganha, visto que proporciona maiores valores negociados. Ela melhora as relações entre receitas e despesas, favorece a diluição de custos fixos, além de contribuir para equilibrar a taxa de ocupação de máquinas e equipamentos, facilita processos automatizados, uma vez que a quantidade produzida contribui para a viabilidade do investimento, possibilitando uma relação ótima entre capital e trabalho, favorecendo uma atuação mais competitiva da empresa (STEINDL, 1990; SCHENEM et al.,2010).

Os efeitos desses processos reduzem custos e aumentam a eficiência, pois possibilitam oferecer produtos a preços menores que elevam as barreiras de entrada para novos competidores. Esses aspectos foram destacados no modelo EstruturaConduta-Desempenho (BAIN, 1951) e no Modelo das Cinco Forças Competitivas (PORTER, 2009), ao abordarem os efeitos das barreiras de entrada na limitação do número de competidores (POSSAS, 1999). Menor número de concorrentes reduz a fragmentação e facilita a obtenção das metas de lucratividade, principalmente quando há equilíbrio de forças competitivas (PORTER, 2009). Esse posicionamento restringe mobilidade interna, limita o crescimento de empresas menores e favorece a formação de grupos estratégicos, que podem ser conceituados como um conjunto de empresas "[...] dentro de um setor, que seguem uma estratégia igual ou semelhante" (HOLEY; SAUDERS; PIERCY, 2011, p. 73) e, assim, atuam para manter suas posições competitivas, restringindo a mobilidade interna no setor. Nessa perspectiva, a presença de economia de escala destaca-se como um pré-requisito para o crescimento das empresas (STEINDL, 1990).

O fator captou também a presença de aspectos internos e estruturais, característicos do modelo de competitividade sistêmica, e, segundo ele, o 
desempenho empresarial depende de um conjunto amplo de aspectos presentes tanto no ambiente interno da empresa quanto fora dele (ROMAN et al. 2012; OLIVEIRA; ROSETO, 2014). Os aspectos internos podem ser controlados e reúnem questões como a estratégia, as formas de gestão, a capacidade de produção, a qualificação dos recursos humanos, a tecnologia utilizada, entre outros. Os aspectos externos podem ou não ser controlados pelas empresas e reúnem tanto questões de ordem estrutural (mercados, concorrência etc.), quanto sistêmicos (políticos, macroeconômicos, sociais etc.)

A competitividade sistêmica, em determinadas perspectivas, ampliou o escopo dos modelos Estrutura-Conduta-Desempenho e Cinco Forças Competitivas, ao estabelecer uma compreensão mais complexa da competitividade, envolvendo ações de ordem pública e privada, em processo de interação dinâmica, que, dependendo de sua combinação, podem induzir a uma situação favorável para o ambiente de atuação empresarial (COUTINHO; FERRAZ, 2002; SANTANA, 2002; SILVA, 2010).

No contexto competitivo das empresas de laticínios, a busca por maiores volumes de vendas revelou-se como uma das principais estratégias utilizadas pelas empresas (CARVALHO, 2011; TAYRA; SILVEIRA, 2011), que foi iniciada em escala mundial no início da década de 1970 e intensificada a partir de 1990 (MARTINS; FARIA, 2006). Percebe-se que essa estratégia se relaciona com a compreensão da competitividade revelada, pois ocorre ex-pós e se confirma a partir da obtenção de maiores participações de mercado (FERRAZ; KUPFER; HAGUENAUER, 1997).

O fator "Gestão Empresarial” foi responsável por 15,89\% da variância, com valores adequados de consistência interna $(\alpha=0,741)$. Esse fator captou as restrições impostas pela política de acesso ao crédito, acesso a mercados interestaduais e às inovações em processos relacionados à competitividade potencial, caracterizando decisões ex-ante, de tal forma que, se obtiverem aceitação social, proporcionarão para as empresas maiores participações de mercado no futuro, melhorando o desempenho competitivo (POSSAS, 1999; ROMAN et al. 2012).

Ao buscar mercados nacionais, as empresas pretendem aumentar os volumes de vendas, uma vez que grandes centros de consumo demandam maiores quantidades ofertadas. A conquista de espaço nessas praças contribui para uma 
relação mais racional de custos logísticos e despesas comerciais, principalmente quanto à utilização da frota, força de vendas e propaganda. Por outro lado, esses mercados expõem as empresas a uma maior ação da concorrência, que eleva as exigências com a diversificação e a qualidade dos produtos, explicando, em parte, o posicionamento competitivo das empresas de laticínios que participaram da pesquisa.

Esse contexto justifica as inovações realizadas em processos, pois mostram a preocupação em se melhorar a qualidade e a produtividade. As inovações reduzem perdas e desperdício e melhoram a qualidade dos produtos, por utilizar processos padronizados. Com isso, há redução de retrabalhos e devoluções por parte dos consumidores. Reforçar esses aspectos favorece uma atuação mais competitiva das empresas por colocá-las em igualdade ou superioridade em relação aos demais competidores.

O terceiro fator, "Ambiente Locacional", obteve 14,89\% da variância e valores adequados de consistência interna $(\alpha=0,671)$. Esse fator exprime as contribuições da localização das empresas, reunindo aspectos competitivos, essenciais para produção agropecuária, como a oferta de matéria-prima e a proximidade dos produtores rurais (FARINA; AZEVEDO; SAES, 1997). O fator captou aspectos relativos à importância dos insumos e à atuação de entidades de classe, associações e sindicatos. A participação das entidades de classe é elemento fundamental para a elaboração de políticas públicas que propiciem conquistas para a região, pois "a luta pelo poder e por recursos entre grupos sociais é o cerne da formulação de políticas públicas" (SOUZA, 2006, p. 39). Assim, entidades fortes, atuantes e participativas na mediação de interesses junto a entidades políticas e econômicas podem contribuir para a competitividade da cadeia de produção, que representa uma atividade econômica importante para se melhorar a qualidade de vida no campo (MATTOS; SANTANA, 2014).

O quarto fator, "Desempenho Competitivo", explicou 11,89\% da variância com consistência interna pouco abaixo da recomendável $(\alpha=0,567)$. Esse fator foi caracterizado pela composição de aspectos estruturais da competitividade sistêmica (evolução do desempenho e políticas públicas). Assim, o fator captou aspectos como evolução das vendas, participação de mercado, empregos gerados e lucratividade 
obtida, características associadas a fatores sistêmicos. A combinação desses aspectos e a presença de sinais diferentes no mesmo fator revelam a atuação prejudicial das políticas públicas na evolução do desempenho das empresas no Estado. As políticas públicas representam uma gama de circunstâncias, que compreendem desde a formação de infraestrutura a questões relacionadas à presença de incentivos fiscais, formação de mão de obra, linhas de crédito e programas de acesso à informação, todos considerados necessários para o aumento de competitividade, de tal forma que sua ausência ou implementação deficiente representam restrições à atividade na região.

Quanto aos resultados do Índice de Desempenho Competitivo (Tabela 3), observa-se que duas empresas apresentaram alta competitividade (10 e 01) e, em termos percentuais, representam 6,7\% (2) dos entrevistados. Considerandose apenas o fator principal, aquele que representa a "Estrutura de Produção", as quatro primeiras empresas $(04,05,01$ e 10) se destacam com relação às demais, evidenciando a importância do volume, capacidade e quantidades produzidas para a competitividade das empresas de laticínios, como ocorre com as commodities em geral. Percebe-se também que, entre as quatro empresas mais competitivas, a Empresa 01, apesar de se posicionar na segunda colocação no ranking, foi a quarta colocada com relação ao fator principal, destacando-se pelo desempenho na gestão (Fator 2) e pelo desempenho competitivo (Fator 4). 
Tabela 3. Índice de Desempenho Competitivo das empresas de laticínios do Pará

\begin{tabular}{|c|c|c|c|c|c|c|c|c|c|c|}
\hline \multirow{3}{*}{$\begin{array}{c}\text { Empresa } \\
10\end{array}$} & \multicolumn{4}{|c|}{ Escore Fatorial Original } & \multicolumn{4}{|c|}{ Escore Fatorial Padronizado } & \multirow{2}{*}{\multicolumn{2}{|c|}{ IDC }} \\
\hline & \multirow{2}{*}{$\frac{\text { Fator } 1}{2,5989}$} & \multirow{2}{*}{$\frac{\text { Fator } 2}{-0,5499}$} & \multirow{2}{*}{$\frac{\text { Fator } 3}{0,9264}$} & \multirow{2}{*}{$\frac{\text { Fator } 4}{0,5056}$} & \multirow{2}{*}{$\frac{\text { Fator } 1}{1,0000}$} & \multirow{2}{*}{$\begin{array}{c}\text { Fator } 2 \\
0,3229\end{array}$} & \multirow{2}{*}{$\frac{\text { Fator } 3}{0,6968}$} & \multirow{2}{*}{$\frac{\text { Fator } 4}{0,6400}$} & & \\
\hline & & & & & & & & & 0,7570 & \\
\hline 01 & 2,0523 & 0,7859 & $-0,4454$ & 0,8870 & 0,8512 & 0,6378 & 0,3964 & 0,7284 & 0,7068 & \\
\hline 05 & 2,3169 & $-0,8358$ & $-0,0497$ & 0,2172 & 0,9233 & 0,2555 & 0,4830 & 0,5732 & 0,6582 & \\
\hline 04 & 2,2899 & 0,1271 & 0,7498 & $-2,2556$ & 0,9159 & 0,4825 & 0,6581 & 0,0000 & 0,6472 & \\
\hline 08 & 0,0769 & 2,1678 & $-0,6502$ & 0,0955 & 0,3137 & 0,9636 & 0,3515 & 0,5450 & 0,4832 & \\
\hline 22 & $-0,7211$ & 2,3224 & 0,2507 & 0,5955 & 0,0965 & 1,0000 & 0,5488 & 0,6609 & 0,4420 & \\
\hline 12 & 0,1822 & 0,2002 & $-1,1175$ & 1,6162 & 0,3423 & 0,4997 & 0,2492 & 0,8975 & 0,4383 & \\
\hline 19 & $-0,8611$ & 0,1272 & 1,7922 & 2,0586 & 0,0584 & 0,4825 & 0,8864 & 1,0000 & 0,4345 & \\
\hline 26 & 0,2552 & $-0,3001$ & $-0,2990$ & 0,8755 & 0,3622 & 0,3818 & 0,4284 & 0,7258 & 0,4321 & \\
\hline 17 & $-0,1658$ & $-0,6338$ & 1,3868 & 0,6652 & 0,2476 & 0,3031 & 0,7976 & 0,6770 & 0,4238 & \\
\hline 13 & 0,2735 & $-0,5976$ & 0,3767 & 0,0980 & 0,3672 & 0,3117 & 0,5764 & 0,5455 & 0,4213 & \\
\hline 09 & 0,2073 & 0,6964 & $-0,3418$ & $-1,0716$ & 0,3492 & 0,6167 & 0,4191 & 0,2744 & 0,4039 & \\
\hline 18 & $-0,3102$ & 0,4711 & 0,1608 & 0,5372 & 0,2083 & 0,5636 & 0,5291 & 0,6474 & 0,4027 & \\
\hline 03 & 0,2734 & 0,1208 & $-0,5655$ & $-0,5116$ & 0,3671 & 0,4810 & 0,3701 & 0,4042 & 0,3957 & \\
\hline 07 & $-0,3887$ & 0,9642 & 0,3925 & $-0,3237$ & 0,1870 & 0,6798 & 0,5799 & 0,4478 & 0,3955 & \\
\hline 06 & $-0,3341$ & 1,4490 & $-0,0336$ & $-1,0235$ & 0,2018 & 0,7941 & 0,4865 & 0,2856 & 0,3838 & \\
\hline 21 & $-0,0565$ & 0,8898 & $-0,6486$ & $-0,6247$ & 0,2774 & 0,6623 & 0,3519 & 0,3780 & 0,3821 & \\
\hline 27 & $-0,3336$ & $-0,1257$ & $-0,7327$ & 0,9748 & 0,2020 & 0,4229 & 0,3334 & 0,7488 & 0,3508 & \\
\hline 20 & $-0,3410$ & $-1,9196$ & 1,4384 & 0,6166 & 0,1999 & 0,0000 & 0,8089 & 0,6657 & 0,3419 & \\
\hline 02 & $-0,1797$ & $-0,0094$ & $-1,5458$ & 0,9295 & 0,2438 & 0,4503 & 0,1554 & 0,7383 & 0,3414 & \\
\hline 16 & $-1,0757$ & 0,5470 & 2,3108 & $-1,1539$ & 0,0000 & 0,5815 & 1,0000 & 0,2554 & 0,3375 & \\
\hline 28 & $-0,2934$ & 0,3536 & $-0,9422$ & $-0,5874$ & 0,2129 & 0,5359 & 0,2876 & 0,3867 & 0,3162 & \\
\hline 23 & $-0,5700$ & $-0,3600$ & 0,2374 & $-0,0805$ & 0,1376 & 0,3677 & 0,5459 & 0,5042 & 0,3128 & \\
\hline 29 & $-0,6072$ & 0,0138 & $-0,4235$ & 0,2814 & 0,1275 & 0,4558 & 0,4012 & 0,5880 & 0,3110 & \\
\hline 14 & $-0,8474$ & $-0,2768$ & 0,5684 & $-0,6510$ & 0,0621 & 0,3873 & 0,6184 & 0,3719 & 0,2750 & \\
\hline 11 & $-0,5938$ & $-0,9973$ & 0,9620 & $-1,6115$ & 0,1312 & 0,2174 & 0,7046 & 0,1493 & 0,2569 & \\
\hline 30 & $-0,9288$ & $-0,3736$ & 0,1381 & $-0,2410$ & 0,0400 & 0,3645 & 0,5242 & 0,4670 & 0,2567 & \\
\hline 15 & $-0,7144$ & $-0,9577$ & $-0,6173$ & 0,5380 & 0,0983 & 0,2267 & 0,3587 & 0,6475 & 0,2531 & \\
\hline 25 & $-0,3686$ & $-1,6308$ & $-1,0231$ & 0,5274 & 0,1924 & 0,0681 & 0,2698 & 0,6451 & 0,2491 & \\
\hline 24 & $-0,8355$ & $-1,6681$ & $-2,2552$ & $-1,8831$ & 0,0654 & 0,0593 & 0,0000 & 0,0863 & 0,0552 & \\
\hline
\end{tabular}

Fonte: pesquisa de campo. 
$\mathrm{Na}$ avaliação geral, ocorreu predominância de empresas posicionadas nos estratos intermediários $(0,4001$ e 0,6999$)$ e baixos (menores que 0,4000$)$, em que se posicionaram 36\% (11) e 57\% (17) das empresas, respectivamente. Os baixos valores para média $(0,3955)$ e mediana $(0,3897)$ indicam baixa competitividade do setor no Estado e recomendam a necessidade de políticas e estratégias específicas que contribuam para o incremento na competitividade das empresas, principalmente as fiscalizadas pela inspeção estadual, uma vez que $75 \%$ (9) delas mostraram menor capacidade competitiva, posicionando-se no estrado de baixa competitividade.

\section{CONSIDERAÇÕES FINAIS}

A pesquisa revelou que a competitividade das empresas de laticínios do Estado está fundamentada na busca por maiores volumes de produção, obtenção de economia de escala e maiores participações de mercado. Para tanto, as estratégias empresariais têm se voltado para a atuação no mercado interestadual, tendo como diretriz principal aumentar a produtividade e melhorar a qualidade dos produtos, apoiadas nas vantagens locacionais, oferecidas pela região. Essas estratégias estão alinhadas aos modelos de competitividade de características estruturalistas, em especial, os modelos Estrutura-Conduta-Desempenho e Cinco Forças Competitivas. Em linhas gerais, a estratégia competitiva das empresas de laticínios foi compatível com a observada em outras regióes do país e bem alinhada ao mercado de commodities.

As condições locacionais têm possibilitado que as empresas alcancem maior desempenho competitivo ao longo do tempo. Esses avanços sofrem com a precariedade de políticas públicas e de fatores que tendem à exaustão, representando riscos ao setor. Entre as empresas, apenas uma pequena parcela se revelou realmente competitiva, predominando níveis intermediários e baixos de competitividade. As empresas que atuam somente no mercado estadual são as menos competitivas e evidentemente necessitam de políticas públicas, direcionadas para reduzir suas deficiências e possibilitar seu crescimento. A manutenção da expansão das empresas de laticínios no Estado demanda atuação conjunta, tanto das empresas quanto dos 
produtores de leite e do governo do Estado. As empresas devem promover incentivos à produção de leite, maior integração da cadeia e atuação do governo no âmbito da formação de infraestrutura e implementação de políticas públicas, especialmente direcionadas para as empresas menores, fiscalizadas pela inspeção estadual.

\section{AGRADECIMENTOS}

Os autores agradecem ao Conselho Nacional de Desenvolvimento Científico e Tecnológico (CNPq) pelo apoio financeiro e concessão de bolsa para a pesquisa.

\section{REFERÊNCIAS}

BAIN, J. Relation of profit rate industry concentration: American manufacturing 1936-1940. Quartely Journal of Economics, v. 65, ago. 1951.

BARROS, G. S. C.; GALAN, V. B.; GUIMARAES, V. A.; BACHI, M. R. P. Sistema agroindustrial do leite no Brasil. Brasília: Embrapa, 2001.

BRITTO, J.; STALLIVIERI, F.; CAMPOS, R.; VARGAS, M. Padrões de aprendizagem, cooperação e inovação em aglomerações produtivas no Brasil: uma análise multivariada exploratória. In: ENCONTRO ANUAL DA ASSOCIAÇÃO NACIONAL DE PÓS-GRADUAÇÃO EM ECONOMIA, 35., 2007. Recife. Anais... Rio de Janeiro: ANPEC, 2007. Disponível em: <www.anpec.org.br/encontro2007/artigos/A07A126. pdf $>$. Acesso em: $10 \mathrm{dez} .2015$.

CARVALHO, G. R. Indústria de laticínios no Brasil. In: STOCK, L. A.; ZOCCAL, R. CARVALHO, G. R.; SIQUEIRA, K. B. Competitividade do agronegócio do leite brasileiro. Brasília: Embrapa. 2011.

COSTA, R.; SILUK, J.; NEUENFELDT JUNIOR, A.; SOLIMAN, M.; NARA, E. A gestão da competitividade industrial por meio da aplicação dos métodos UP e multicritério no setor de frigorífico de bovinos. Revista Chilena de Ingeniería, v. 23, n. 3, p. 
383-394, 2015. Disponível em: <http://www.scielo.cl/scielo.php?pid=S071833052015000300007\&script=sci_arttext. >. Acesso em: 02 dez. 2015.

COUTINHO, L.; FERRAZ, J. C. Estudo da competitividade da indústria brasileira. Campinas: Papirus, 2002.

DILLON, W. R.; GOLDSTEIN, M. Multivariate analysis: methods and applications. New York: John Wiley \& Sons, 1984.

FARINA, E. M. M. Q.; AZEVEDO, P. F.; SAES, M. S. M. Competitividade: mercados, estado e organizações. São Paulo: Singular, 1997.

FERRAZ, J. C.; KUPFER, D.; HAGUENAUER, L. Made in Brasil: desafios competitivos para a indústria. Rio de Janeiro: Campus, 1997.

GAMA, Z, J. C.; SANTANA, A. C.; MENDES, F. A. T.; KHAN, A. S. Índice de desempenho competitivo das empresas de móveis da Região Metropolitana de Belém. Revista de Economia e Agronegócios, v. 5, n. 1, p. 127-159. Disponível em: <http://www. repositorio.ufc.br:8080/ri/bitstream/123456789/1305/1/2007_art_zjcgama.pdf > . Acesso em: 12 nov. 2015.

HAIR JUNIOR; J. F.; ANDERSON, R. E; TATHAM, R. L.; BLACK, W. C. Análise multivariada de dados. Porto Alegre: Bookman, 2009.

HOOLEY, G. J.; SAUNDERS, J. A.; PIERCY N. F. Estratégia de marketing e posicionamento competitivo. São Paulo: Prentice Hall, 2011.

HORTA, R.; SILVEIRA, L.; CAMACHO, M. Competitividad e innovación em la indústria manufacturera em el Uruguay. Revista CTS, v. 10, n. 28, p. 23-49, jan. 2015. Disponível em: <http://www.revistacts.net/volumen-10-numero-28/294articulos/633-competitividad-e-innovacion-en-la-industria-manufacturera-en-eluruguay >. Acesso em: 10 dez. 2015.

MARTINS, G. A. Manual para elaboração de monografias e dissertações. São Paulo: Atlas, 2010. 
MARTINS, P. C.; FARIA, V. P. Histórico do leite no Brasil. In: CÔNSOLI, M. A.; NEVES, M. F. Estratégias para o leite no Brasil. São Paulo: Atlas, 2006.

MATTOS, C.A.C.; SANTANA, A.C.S. As contribuições da pecuária leiteira para os agricultores familiares: um estudo no sudeste do estado do Pará. Extensão Rural, v. 21, n. 1, p. 56-71 jan./mar. 2014. Disponível em: < http://cascavel.ufsm.br/revistas/ ojs-2.2.2/index.php/extensaorural/article/view/7780 > . Acesso em: 12 nov. 2015.

OLIVEIRA, M.A.S.; ROSSETO, A. M. Modelo integrado de sustentabilidade e competitividade em meio de hospedagem. Rosa dos Ventos, v. 6, n. 4, p. 546563, out./dez. 2014. Disponível em: <http://www.ucs.br/etc/revistas/index.php/ rosadosventos/article/viewArticle/2758>. Acesso em: 25 nov. 2015.

PORTER, M. Competição: on competition. São Paulo: Campus, 2009.

POSSAS, S. Concorrência e competitividade: notas sobre estratégia e dinâmica seletiva capitalista. São Paulo: Hucitec, 1999.

SANTANA, A. C. Competitividade sistêmica das empresas de madeira da região Norte. Belém: FCAP, 2002.

SANTANA, A. C. Índice de desempenho competitivo das empresas de polpa de frutas do Estado do Pará. Revista de Economia e Sociologia Rural, v. 45, n. 3. p. 749775 jul./set. 2007. Disponível em: < http://www.scielo.br/scielo.php?pid=S010320032007000300009\&script=sci_arttext $>$. Acesso em: 12 dez. 2015.

SANTANA, A. C.; SILVA, I. M.; SILVA, R. C. S.; OLIVEIRA, C. M.; BARRETO, A. G. T. A sustentabilidade do desempenho competitivo das madeireiras da região MamuruArapiuns, estado do Pará. Teoria e Evidencia Econômica, v. 15, n. 33, p.9-36, jul./ dez. 2009. Disponível em: < http://www.upf.br/cepeac/download/Revista\%20TEE_ an15_n33_09.pdf>. Acesso em: 08 nov. 2015.

SANTOS, M. A. S.; SANTANA, A .C. S.; RAIOL, L. C. B.; LOURENÇO JUNIOR, J. B. Fatores tecnológicos de modernização da pecuária leiteira no estado do Tocantins. Revista em Agronegócios e Meio Ambiente, v.7, n.3, p. 591-612, set./dez. 2014. 
Disponível em: <http://periodicos.unicesumar.edu.br/index.php/rama/article/ view/2115 > . Acesso em: 20 out. 2015.

SCHENEM, A.; BERTOLINI, A. L.; UVEDA, V. R.; BARCELLOS, P. F. P. Estratégia e competitividade sistêmica: estudo de caso do setor vitivinícola da serra gaúcha. Revista de Administração, Contabilidade e Economia, v. 9, n. 1-2, p. 67-90, jan./ dez. 2010. Disponível em: <http://www.editora.unoesc.edu.br/index.php/race/ article/download/551/pdf_102. > . Acesso em: 10 out. 2015.

SEBRAE - SERVIÇO BRASILEIRO DE APOIO ÀS MICRO E PEQUENAS EMPRESAS. Critérios e conceitos para a classificação de empresas. Disponível em: $<\mathrm{http}: / /$ www.sebrae-sc.com.br/leis/default.asp?vcdtexto $=4154>$. Acesso em: 15 nov. 2015.

SILVA, C. L. Competitividade na cadeia de valor. Curitiba: Juruá, 2010.

SOARES, A. C. L. G.; GOSSON, A. M. P. M.; MADEIRA, M. A. L. H; TEIXEIRA, V. D. S. Índice de desenvolvimento municipal: hierarquização dos municípios do Ceará no de 1997. Revista Paranaense de Desenvolvimento, n. 97, p. 71-89, set./dez. 1999. Disponível em: <http://www.ipardes.pr.gov.br/ojs/index.php/revistaparanaense/ article/view/260> . Acessado em: 20 de nov. 2015.

SOUZA, C. Políticas públicas: uma revisão da literatura. Sociologias, v. 8, n. 16, p. 20 - 45, jul./dez. 2006. Disponível em: <http://www.scielo.br/scielo.php?script=sci. $>$. Acesso em: 20 out. 2015.

STALLIVIERI, F.; CAMPOS, R. R.; BRITTO, J. N. P. Indicadores para a análise da dinâmica inovativa em arranjos produtivos locais: uma análise exploratória aplicada ao arranjo eletrometal-mecânico de Joinville/SC. Estudos Econômicos, v. 39, n. 1, p. 185 - 219, jan./mar. 2009. Disponível em: < http://www.scielo.br/pdf/ee/v39n1/ v39n1a07.pdf>. Acesso em: 10 dez. 2015.

STEINDL, J. Pequeno grande capital. São Paulo: Hucitec, 1990.

TAYRA, F.; SILVEIRA, C. D. Setor de distribuição de lácteos: a importância dos supermercados. In: STOCK, L. A.; ZOCCAL, R. CARVALHO, G. R.; SIQUEIRA, K. B. 
Competitividade do agronegócio do leite brasileiro. Brasília: Embrapa, 2011.

THOMÉ, K. M.; FERREIRA, L. S. Competitividade e estrutura de mercado internacional de café: análise de 2003 a 2012. Coffee Science, v. 10, n 2. p. 184-194, abr.jun. 2015. Disponível em: < http://www.coffeescience.ufla.br/index.php/Coffeescience/ article/view/821>. Acesso em: 10 dez. 2015.

Recebido em: 23 de dezembro de 2015 Aceito em: 21 de outubro de 2016 